\title{
0 "SER-MÃE" DE CRIANÇA COM MALFORMAÇÃO: UM ESTUDO FENOMENOLÓGICO
}

THE MALFORMED CHILD 'MOTHER-BEING: A PHENOMENOLOGICAL STUDY.

Mirian Caliope Dantas Pinheiro ${ }^{1}$

RESUMO: A temática deste estudo refere-se à vivência de mães com filhos portadores de malformação congênita e traz uma análise sobre as suas reações diante do mesmo. Trata-se de um estudo descritivo segundo a linha qualitativa com a abordagem fenomenológica. E, para tanto, foram realizadas entrevistas e aquisição dos depoimentos. Fez-se a análise em busca do sentido, da direção destas mães, ou seja, a sua maneira de ser, de estar no mundo, partindo dos significados (unidades de significação), indo ao sentido, à luz do referencial filosófico de Martin Heidegger, objetivando caracterizar o Ser-Mãe em seu cotidiano.

UNITERMOS: Fenomenologia - Existencialismo - Anomalia fetal.

\begin{abstract}
The theme of this research refers to children suffering congenital malformation through an analysis of their mothers' reactions in dealing with such a situation. It deals with a descriptive study along the qualitative line through the phenomenological approach. In order to attain that purpose, interviews were made and data collected. The analysis was built under the view of meaning, the orientation of those mothers, i.e. the outlook of the world from their perspective, which was tracked from the meanings (units of meaning) to actual sense based on the philosophical insight of Dr. Martin Heidegger, aiming at characterizing the mother-being in her daily life.
\end{abstract}

KEYWORDS: Phenomenology - Existentialism - Phetal anomaly.

\footnotetext{
${ }^{1}$ Aluna do Curso de Doutorado da Escola de Enfermagem Anna Nery-UFRJ. Mestre em Enfermagem pela Universidade do Rio de Janeiro - UNIRIO. Professora Assistente da Universidade de Fortaleza - UNIFOR. Este artigo é parte da dissertação de mestrado.
} 


\section{INTRODUÇÃO}

Preocupamo-nos com as mães que vivenciam a experiência de ter filhos portadores de malformação congênita e, por isso, buscamos compreendê-las, não só na condição de Enfermeira mas como ser humano e mulher, que tem a possibilidade da gestação. Observamos situações de apreensão das mães, durante nossa experiência como docente, lecionando a disciplina de Enfermagem Pediátrica e acompanhando alunos no campo da prática. Certa vez, ao aproximarmo-nos da mãe que segurava o filho nos braços, o qual apresentava malformação congênita (tipo lábio leporino), percebemos muita ansiedade nela. A sua expressão era de pânico e inquietação, talvez por não saber lidar com a situação ou por repulsa. Momentos depois, conversando com ela, evidenciamos o seu descontentamento quando nos falou: "...ele é tão feio, meu marido nem gosta dele... Ficou doente de pneumonia e a avó o trouxe para o hospital...". Em outra ocasião, presenciamos uma mãe que assumia, com muito amor e carinho, a filha portadora de hidrocefalia congênita, e assim se expressava: "..esta filha é a minha vida, é tudo que eu tenho! ...".

Tomamos conhecimento de outra situação em que uma enfermeira e um médico discutiam sobre como informar à mãe que seu filho nascera com malformação congênita mutilante (sem a mão direita). $O$ médico dirige-se à mãe, informa-Ihe que o bebê nascera com um problema, mas não Ihe dissera qual. Ela Ihe pergunta: ele pode mamar?. Ele responde que sim. Então traga-o para que eu o alimente,... minutos depois, a criança está em seus braços. Ela olha o filho com muita atenção, percorrendo parte a parte do seu corpo e, inspecionando-o atentamente, percebe o defeito e diz, segurando e acariciando a mão esquerda do bebê, "ele aprenderá a escrever com esta mão!".

Os fatos relatados conduziram-nos a uma reflexão conflituosa, já que as mães demonstraram reações diferenciadas diante dos eventos.

Nossa experiência com estas mães permite pensar e refletir sobre a sua vivência:

- Quão ansioso é o momento em que mães esperam ver o rosto, o corpo do "pequeno ser" que desabrochou em seu ventre e que, na possibilidade do seu existir, alinhou ou desalinhou, não se formando perfeito.

- Quão sofrido é o momento do nascimento de um filho malformado, cujo sonho de perfeição velava ontem, mas que hoje desvela-se frágil e deformado.

- Quão triste é ver que o "ser-nascido" não corresponde ao "ser-sonhado"!

Elas podem fazer questionamentos como: Por que eu? Por que isso foi acontecer comigo? Serei eu a culpada? Foi castigo de Deus? Como posso aceitar e amar aquele que eu não reconheço, aquele que não corresponde ao meu sonhar? Tenho que levá-lo para casa, acolhê-lo e amá-lo como ele precisa. 
Minha familia e meus amigos vão olhá-lo com espanto! O que lhes dizer? Alguém me ajude!.

Essas reflexões levaram-nos a questionar por que a mãe vivencia o evento desta ou daquela maneira? Quais seriam essas maneiras?. Diante de nossa preocupação direcionada para mães de criança com malformação congênita, passamos a investigar. Buscamos, através deste estudo, compreender o que se passa e o que representa para elas o nascimento desse filho.

Acreditamos que esse estudo venha a contribuir para a melhoria da assistência de saúde preventiva a esta população, pois observamos na prática que nós profissionais de enfermagem não estamos aptos para assistir esta clientela. O despreparo técnico e científico são visíveis nesta área, falta-nos preparo psicológico para atendê-los. Muitas vezes fugimos da situação. Não nos envolvemos ou somos insensiveis, frios, atentos apenas aos aspectos científicos dos casos a serem investigados e estudados, sem que tenhamos preocupações com o ser humano em si mesmo.

Trabalhar este tema numa abordagem fenomenológica com o referencial Heideggeriano nos proporcionou uma nova maneira de ver o ser humano. Procurando assistir ao binômio mãe-filho de uma forma mais humanizada, compreendendo-a em seu vivenciar, em seu modo de ser "com-o-filho" e com os outros. E, nesta abordagem, esforçarmo-nos para levar a mãe a se assumir, no seu modo mais próprio de ser, sendo, existindo no mundo com o filho malformado. No pensamento Heideggeriano, o existir é concretar o modo de ser mais próprio, ser "pre-sença" no mundo, na vida das pessoas ("ser-com-o-outro"), estando ou não presente, mas sendo existência para os outros. Estar sempre sendo no mundo.

A partir desse olhar atentivo próprio da Fenomenologia, mergulhamo-nos na intimidade do Ser-Mãe, buscamos conhecê-la na sua totalidade e, assim, pudemos compreendê-las na sua temporalidade, através da interpretação dos significados expressos nos seus depoimentos, analisados e interpretados à luz de um referencial filosófico. Neste estudo, utilizamos o referencial de Martin Heidegger. "Hermenêutica Compreensiva" (compreensão e interpretação) para ir dos significados (unidades de significados) ao sentido, captar o modo de ser, o campo das possibilidades do modo de ser humano (ontológico) ou da coisa (ôntico).

\section{REFERENCIAL FILOSÓFICO}

A abordagem fenomenológica tem sido utilizada nas ciências humanas, principalmente na Psicologia. É um método que se caracteriza por examinar os conteúdos existentes, sem se preocupar em determinar-aprioristicamente se estes são reais ou irreais, ideais ou imaginários o qual teve como precursor $E d$ mund Husserl ${ }^{2}$.

As bases da fenomenologia Husserliana são a intencionalidade da consciência que está direcionada para algo.

\footnotetext{
${ }^{2}$ MARTINS, J. \& BICUDO, M. A. V. A Pesquisa em Qualitativa em Psicologia Fundamentos e Recursos Básicos. São Paulo, Morais, 1989.
} 
A fenomenologia de Husserl funda-se na experiência vivida do sujeito, um retorno às coisas mesmas, à apreensão da essência do fenômeno, à percepção da consciência a nivel da maneira de conter o mundo ${ }^{3}$. Husserl compreende que:

"quando um sujeito se torna consciente de alguma coisa tem um caráter direcional, que implica o "movimento" ativo da consciência para além de si mesmo a fim de incluir (isto é, "pretender") um objeto dentro de sua esfera. O objeto intencional, o que Husserl denomina de noema, é simplesmente um correlato do ato de pretender, ou noeses ${ }^{\prime \prime}$.

Em sua proposta, ele fala de uma filosofia transcendental que coloca em suspensão o conhecimento do mundo natural, deixar o conhecimento de lado, mas não negá-lo; suspender a facticidade "Epoché", fazendo a redução fenomenológica para buscar os significados e, com isso, chegar à essência do fenômeno, o "eidos" através da redução eidética. A redução transcendental de que fala Husserl busca o sentido da consciência. Têm-se em Husserl dois métodos possiveis: a análise ontológica do nosso Lebenswelt e a análise fenomenológica transcendental ${ }^{5}$.

Martin Heidegger, tendo sido discipulo de Edmund Husserl, assimilou alguns de seus conceitos. A sua obra, "Ser e Tempo", apresentada em dois volumes, é um marco na história da filosofia ocidental, tornando-se um desafio para o nosso século. É a fenomenologia das essências: busca o sentido do ser, do "Dasein", do "ser-aí" que se dá em seu sentido, em sua maneira de ser, de existir "no-mundo", de apreender o mundo.

Segundo ele, o vivenciar do homem é analisado a partir de preceitos que marcam a sua existência e que este, ao se "pro-jetar", está aí, sem saber o porquê. Este homem, em sua condição básica de "ser-no-mundo", desenvolve-se, estabelece relações "com-o-outro", "com-o-mundo", agindo e reagindo em suas possibilidades existenciais, ou seja, na autenticidade ou na inautenticidade do seu ser. Busca realizar aquilo que ainda não é, e, muitas vezes, é desviado do caminho existencial, o eu, confrontando-se com o outro, destruindo-se, anulando-se, deixando de tornar-se "si mesmo" e se tornando o que os outros desejam que seja: impessoal, inautêntico em sua vivência.

O homem Ec-sistente ("Dasein"), aberto no "pre" da "pre-sença", se mostra na disposição, na compreensão e no discurso. Portanto, o modo de ser do homem é a abertura. As dimensões vivenciais cotidianas em que se funda a existência do homem em sua maneira típica de existir, no seu modo de ser no tempo público no mundo de todos, mostram a mobilidade da "de-cadência" do ser em

\footnotetext{
${ }^{3}$ Idem.

${ }^{4}$ GORMAN, R. A. A Visão Dual. Trad. Livia Nevis de Holanda Barbosa, Rio de Janeiro, Zahar, 1979. p. 29.

${ }^{5}$ GORMAN, R. A. (1979. p. 31 - 39).
} 
sua tentação, tranqüilidade, alienação e aprisionamento. E este modo de ser cotidiano se caracteriza pelo "falatório", "curiosidade" e "ambigüidade".

Podendo ou não deste processo, despertar da existência inautêntica ("onde o homem se entende a partir do que ele não é"6) para a angústia, que é a própria existência do homem. É a luta consigo mesmo para manter-se na autenticidade do ser que ele é, do ser próprio, do "ser-no-mundo" que, na possibilidade do seu cotidiano, desperta, transcende e dá sentido à vida, tornando-se existência autêntica ("onde o homem assume seu ser e luta para impor-se tal como é"7).

Na obra "Ser e Tempo", Martin Heidegger utiliza-se de uma fábula para fazer a auto-interpretação da "pre-sença" como "cura", a cura não só no sentido do "cuidado" e a "dedicação" mas também de um "esforço angustiado". O ser humano, como existência "no-mundo", "projeta-se" "no-mundo", está "nomundo", é o próprio mundo. Entretanto, não é algo, se dá à maneira de algo, não tem mais a noção de racionalidade, pois não está diante do mundo, mas "nomundo".

A investigação fenomenológica em Heidegger é uma "hermenêutica" compreensiva, porque se interpreta o relato, ou seja, compreensiva porque esta interpretação não é constitucional, mas sim um movimento de desvelamento de um sentido e direção velados. É fenomenológica porque se situa a nível do fenômeno ou experiência concreta do vivido, isto é, segundo as próprias palavras de Heidegger, "do que se mostra em si mesmo". E estes são desvelados através do discurso e do silêncio, que se concreta no tempo e no espaço fenomenológico.

O humano, o ente dotado de ser da "pre-sença", é "um ser estritamente temporal, por ser histórico e por ter uma limitação ontológica, que é a morte". Este ser, segundo Heidegger, situa-se em um tempo, que não é cronológico e sim um tempo existencial e no espaço.

O tempo ocorre simultaneamente em três momentos, a saber: passado é a facticidade, também não significa dizer uma coisa que passou, ficou para traz, mas que, ao retomar o passado, o ser se projeta para o futuro; presente é o decaimento, tendência do ser humano a se projetar na inautenticidade; futuro é o agora que não chegou cronologicamente, "eu sou o meu futuro ao sair dè mim, abrindo-me para as possibilidades. O humano é o seu passado, seu presente e o seu futuro, é a historicidade de si mesmo existindo "no-mundo"

O espaço humano caracteriza-se pelo "des-afastamento" e orientação do "ser-no-mundo". O des-afastamento é a capacidade do homem de superar a distância e aproximar-se dos entes, trazer a si os entes fechados em si mesmo;

\footnotetext{
BEAINI, T. C. (1981, p.85).

Idem, p.85.

HEIDEGGER, M. (1989. p. 264)

MORA; J. F. (1982, p.176).

${ }^{10}$ BEAINI, T. C. (1981. p. 41 - 42).
} 
a orientação, cada coisa está ao lado da outra, o relacionar-se constante com o mundo. Este des-afastamento e orientação do homem compreende-se no seu espacializar; o espaço dos entes intramundanos que é o ôntico-existenciário; e o espaço dos entes dotados de ser da "pre-sença", ser humano que é o ontológico-existencial.

Do método Husserliano, Heidegger assume a instância do fenômeno, a redução fenomenológica em busca do significado para obter o sentido (o eidos redução eidética) à luz da totalidade. Ele fez uma ontologia que reflete o ser e o caracteriza aí, enquanto existência.

\section{Nosso Caminhar Apoiado na Abordagem Fenomenológica}

Neste trabalho, utilizamo-nos da abordagem qualitativa e da investigação fenomenológica, pois a fenomenologia permite "mostrar, descrever e compreender os motivos presentes nos fenômenos vividos e se mostram e se expressam de si mesmos na entrevista empática"11.

A análise compreensiva foi realizada à luz de Martin Heidegger em virtude de este autor ter desenvolvido seus estudos buscando uma ontologia, "estudo do ser enquanto ser", ser, que no pensamento heideggeriano, "é a maneira como algo se torna presente, manifesto, entendido, percebido, compreendido e, finalmente, conhecido para o ser humano, para o "ser-ai"". ou "Dasein"12.

Foi através desse mergulhar na dimensão cotidiana dos sujeitos vivenciadores das experiências que pudemos perceber os fenômenos ônticos ("tudo o que é percebido, entendido, conhecido de imediato"), as diferentes situações, os aspectos ontológicos que têm o sentido do ser ("é aquilo que possibilita as várias maneiras de algo tornar-se manifesto, presente, criado, produzido, atuando sentindo...") $)^{13}$, a maneira, o modo de ser da "pre-sença", ou seja, como as mães se mostram em si mesmas, na vivência com este filho.

Fenômeno, segundo as próprias palavras de Heidegger, "é o que se mostra em si mesmo". E, nesta situação, podemos dizer que o fenômeno situado está velado na vivência das mães, manifestações ou reações maternas diante da malformação ${ }^{14}$.

A "manifestação" de que fala Heidegger é algo que em si mesmo não se mostra, ou seja, é o anunciar de algo e não o seu "mostrar-se". A manifestação vela o fenômeno, sendo que manifestação nunca é fenômeno, oculta o mostrarse em si mesmo. A manifestação, portanto, enquanto o que anuncia o fenômeno, não é uma simples aparência, isto é, não é um mostrar-se como sendo o que não é em si mesmo ${ }^{15}$.

\footnotetext{
${ }_{11}^{11}$ Prefácio da doutora CAPALBO no livro da Anésia de Souza Carvalho. (1991, p.6).

12 BEAINI, T. C. (1981. p. 25).

13 HEIDEGGER, M. Ser e Tempo. Trad. Márcia de S. A. 3ed. , Petrópolis, Vozes, 1989. p. 22.

${ }^{14}$ ANOTAÇÕES DE AULA. Disciplina de Filosofia Contemporânea. Curso de Especialização em Enfermagem da UERJ, ministrado pela Filósofa Telma Aparecida Donzelli, segundo semestre de 1994.

${ }^{15}$ ANOTAÇÕES DE AULA. Telma Aparecida Donzelli, segundo semestre de 1994.
} 


\section{ObtençÃo dos Depoimentos Maternos}

Este estudo foi realizado no ambulatório da genética do Instituto Fernandes Figueira da Fundação Oswaldo Cruz, com mães de crianças portadoras de malformações congênitas por meio da entrevista fenomenológica através da obtenção de seus depoimentos.

Iniciamos as entrevistas, fazendo apresentações, mantendo uma conversa descontraída, amigável, empática e, conforme a receptividade, solicitamos a participação delas. A entrevista ocorreu em um clima de empatia, ou seja, interação mediada por sentimentos que aproximam as pessoas e permitem chegar ao sentimento do outro. Porém, não significa viver o sentimento, mas sim chegar-se ao outro. "Só assim, o outro será apreendido como estando aí em pessoa; nas suas manifestações, na linguagem e no gesto de seu corpo"16.

A empatia permitiu-nos compreender as mães, percebendo-lhes os gestos em seu movimento existencial. Utilizamos questionamentos que favoreceram a aquisição dos depoimentos. São eles: Como foi o encontro, você e o pai do seu filho(a)? - e a gravidez?... Isso fez com que o diálogo fluisse naturalmente. Ficamos atentos para não usar questões diretivas, não interferindo em suas respostas e, por fim, a pergunta fundamental deste estudo: - o que significa este filho para você?.

A técnica da entrevista possibilitou-nos a aquisição dos depoimentos maternos. Utilizamo-nos da forma de descrição e transcrição, ao invés de gravações, evitando a inibição por parte das mães. Efetuamos as anotações no diário de campo, após cada entrevista.

Os depoimentos maternos foram nomeados por pseudônimos (nome de flor), já que as descrições revelaram uma história de vida por demais dolorosa. E compreendemos a importância de preservá-las.

O número de entrevistas não obedeceu a regras estatísticas significativas, pois o que predominou foi a qualidade da vivência projetada nas falas das mães e os dados transcendentais espaço-tempo destes sujeitos fenomenologicamente.

O encontro investigadora e depoentes forneceu a trajetória. O conhecimento factual foi colocado em suspensão, redução fenomenológica ("Epoché" que significa suspensão de todos os "a priores", todos os pré-conceitos).

Após a consecução dos discurso e silêncio maternos, descrevemos as falas e, em seguida, fizemos leitura e releitura das descrições para obtenção dos si-

\footnotetext{
${ }^{16}$ CAPALBO, C. A História do Ser Humano segundo Merleau-Ponty. Rev. Bras. Filosofia, São Paulo, v. 39, n. 157, p. 3 - 17, Jan/Fev/Mar, 1990.
} 
gnificados e, assim, as unidades de significações, para se fazer a interpretação à luz de Heidegger. Para ele, o ato de "interpretar não é tomar conhecimento do que se compreendeu, mas elaborar as possibilidades projetadas na compreensão ", para a interpretação do sentido das mães, pois "sentido é a perspectiva em função da qual se estrutura o projeto pela posição prévia, visão prévia e concepção prévia. É a partir dela que algo se torna compreensivel como algo", presente, "ser-aí", sendo aí. "no-mundo". A essência do fenômeno foi buscada por meio da redução eidética.

O referencial Heideggeriano forneceu-nos os fundamentos dessa interpretação ou hermenêutica, que é o caráter fenomenológico da interpretação. Detectamos as características existenciais das mães na dimensão vivencial. Vejamos a análise compreensiva.

\section{ANÁLISE COMPREENSIVA DOS DEPOIMENTOS MATERNOS ${ }^{17}$.}

Martin Heidegger, em sua obra "Ser e Tempo", analisa o fenômeno da vivência cotidiana, caracterizando o homem, "o humano" ${ }^{18 ", ~ o ~ " D a s e i n ", ~ o ~ " s e r-a i " ~}$ situado no "mundo-da-vida-cotidiano". O "ser-aí", enquanto existência, é essencialmente possibilidade de ser e, sendo "no-mundo", não se dá como algo, como coisa, e sim como um ser possivel, um poder ser como "abertura". E, nessa abertura, poderá decidir-se pela "autenticidade", sendo si mesmo; ou ainda pela "inautenticidade", alienação de si mesmo.

O "mundo-da-vida-cotidiano" é, segundo Heidegger, o mundo de todos, o mundo público, o mundo do impessoal, cujo sentido e direção do ser fundam-se no descompromisso com o ser do outro, da coisa e de si mesmo, configurando um existir pautado na "inautenticidade".

O existir cotidiano é inerente ao ser humano, diz Heidegger, porque não se pode dele libertar. Entretanto, é, através desse movimento existencial, que se "desvela" o ser em si mesmo, em um movimento de "autenticidade".

O sentido da situação vivencial, ou seja, o deslocamento para si mesmo de sua situação no mundo é, para Heidegger, um modo existencial fundamental, modo que caracteriza ontologicamente o homem em sua analítica existencial ("ontológico-existencial"). Ela se ocupa das diferentes situações que denomina de "ôntico-existenciário", em que há o desvelamento do ser humano na sua situação existencial e velado. A interpretação fenomenológica busca, essencialmente, este desvelamento, e faz isto indo do que é revelado a um conceito existencial.

\footnotetext{
${ }^{17}$ FROSSARD, Selma. As Dimensões do Mundo da Vida e a Formação Profissional do Assistente Social. Escola de Serviço Social - UFRJ, 1992. p.74 - 96.

Esta análise foi inspirada na Dissertação de Mestrado da Selma Frossard, desenvolvida sob orientação de Telma Aparecida Donzelli.
} 
Partindo da analítica existencial de Heidegger, passamos à reflexão sobre o tema, analisando o objeto de estudo, ou seja, as reações maternas diante do filho portador de malformação congênita. No campo "ôntico-existenciário", as mães se mostram enquanto "entes ${ }^{19}$ ", a maneira da aparência, da manifestação, ou seja, reações que vêm de encontro ao ser; no campo "ontológico-existencial" é o que caracteriza o "ser", a maneira como ela reage, a maneira própria dela "ser-no-mundo", o seu modo de ser na situação.

Encontramos, nos depoimentos, as descrições, características e expressões que denotam a maneira do cotidiano, do existir inautêntico. E encontramos também, em um dos discursos maternos, o modo de existir autêntico, o qual comentaremos ao final das análises.

Passaremos às unidades de significações e aos discursos maternos que as originaram e, em seguida, à nossa interpretação e às citações de Heidegger para cada situação específica. Vejamos primeiramente as situações do vivenciar inautêntico das mães.

- A nível da vivência, a mãe, enquanto ser que se abre em seu "pre" da "pre-sença", deixa-se levar pela "inautenticidade", na disposição do "temor" por meio da culpa.

\section{Observemos o discurso de Margarida:}

“...Falei com o meu namorado e ele achou melhor fazer o aborto. Ensinaramme um remédio bom pra fazer descer, preparo de quinino e citotec e nada...! só deu uma diarréia. Então, resolvi assumir a gravidez, contei para meus pais, só não falei que tomei os remédios...

\section{...Quando o médico falou hoje que N. nasceu assim, porque eu tomei os re- médios, me deu uma vontade de chorar,... pensei..., meu Deus o que foi que eu fiz!. Não acredito que foi dos remédios, porque tem muitas mulheres grá- vidas que tomam remédios, drogas, fumam maconha e os nenés nascem normais. Isso é a vontade de Deus...".}

Esta mãe, o "ser-ai" vivenciando o dia-a-dia com o filho portador de malformação, demonstra sentimento de culpa em relação ao filho. Está culpa denota a fuga, o esquivar-se da situação em que foi projetada, o "estar-lançado". A fuga revela, no campo "ôntico-existenciário", as diferentes situações e, no campo "ontológico-existencial", as possibilidades existenciais veladas na vivência, desvelando, no que a pessoa procura fugir, desvelando o "ser-aí" entregue à sua situação existencial e velada, ou seja, à culpa. Podemos notar que o sentimento

\footnotetext{
${ }^{18}$ BEAINI, T. C. $(1981$, p. 18 - 19)

${ }^{19}$ BEAINI, (1981, P.24.).
} 
de culpa implícito no discurso denota o fenômeno do "humor" enquanto "temor". É ao esquivar-se que ela se abre em seu ser no "temor", pois aquilo que ameaça está à mão, é conhecido. Sobre o "humor", Heidegger nos diz:

“...Na maior parte das situações ôntico-existenciárias, a pre-sença se esquiva ao ser que se abre no humor; do ponto de vista ontológico-existencial, isso significa: naquilo de que o humor faz pouco caso, a pre-sença se descobre entregue à responsabilidade do pre. É no próprio esquivar-se que o pre se abre em seu ser" (Heidegger, p.189, 1989).

"... Apenas o que é na disposição do temor, o näo temor, pode descobrir o que está à mão no mundo circundante como algo ameaçador. O estado de humor da disposição constitui, existencialmente, a abertura mundana da presença..."(Heidegger, p.192; 1989).

- A mãe, em sua abertura como "ser-no-mundo" ao modo da disposição, "teme" o problema do filho e nega a malformação.

Acácia em seu discurso expressa:

"...percebi logo que ela tinha um problema nos olhos, era fundo, olhei para ela e comecei a chorar...ai os médicos disseram que ela nasceu sem os olhos...

...Tenho que me conformar, não posso fazer nada, já estou me conformando...é o jeito, pensei que ela pudesse enxergar um dia, fazia operação e ficava boa. Quando chora, sai lágrimas, pensei que isso era porque tinha olhos e que havia jeito de enxergar um dia....".

Com relação ao "temor", esta mãe sempre temeu a malformação da filha. Procurava negar de todas as formas e, em momento algum, pronunciou o fato de a filha ser cega. Preferiu imaginar que ela poderia enxergar um dia.

Segundo Heidegger, o que se teme é um ente que vem ao encontro do ser, é o temivel, aquilo que tem caráter de ameaça. Em sua compreensão, a mãe "pre-sença" "no-mundo" o considera ameaçador, pois ela não aceita que a filha seja sega e não pode conceber a idéia de que ela não irá enxergar jamais. $O$ problema, a malformação, anoftalmia bilateral, faz com que a mãe negue a situação em que foi lançada "no-mundo". A reação materna diante da situação revela, no espaço "ôntico-existenciário", a negação, e, no espaço "ontológicoexistencial", revela as possibilidades existenciais veladas na vivência, desvelando o "ser-ai" entregue à sua situação existencial e velada, desvelando o ser-aí entregue ao "temor". O temor, segundo Heidegger, é:

"O que se teme, o "temível", é sempre um eñte que vem ao encontro dentro do mundo e que possui o modo de ser do manual, ou do ser simplesmente dado ou ainda da co-pre-sença. Não se trata de relatar onticamente o ente que, na maior parte das vezes e das diversas formas, pode se tornar "temível" (Heidegger, p.195,1989). 
O "Ser-Mãe" de Criança com Malformação:...

- A mãe demonstra vergonha, enquanto "ser-no-mundo-cotidiano" aberto no "pre"da "pre-sença" e "de-cai" na "inautenticidade" pela "ambigüidade" do "falatório" e da "curiosidade".

Vejamos o discurso de Dália:

“...Sei que ele não vai enxergar com esse olho, só não quero que fique feio, fundo. O médico disse que depois, quando ele estiver maior, pode botar uma prótese e ninguém vai notar. Não me importo, só penso nele quando crescer e tiver coleguinhas, não quero que sofra. Gosto dele de qualquer jeito...".

A mãe procura esconder que sente vergonha do filho, pois ele apresenta encefalocele na região frontal fazendo compressão no olho esquerdo, e genitália ambígua, dando uma aparência feia. Ela diz que não se preocupa, gosta dele de qualquer jeito, entretanto, teme pelo que os outros vão pensar e falar. Esta "ambigüidade", que se expressa no "falatório", no "se diz que" da tagarelice humana,' no descompromisso consigo mesmo, é o modo próprio da convivência. Esta mãe deixa-se "de-cair" no impessoal, no mundo de todos, no tempo público, na insolidez de sua própria "pre-sença" no mundo como tenta̧̧ão, mantendo-se presa à sua "de-cadência". Nesta situação, a mãe, "em sua abertura, instala-se nos modos de deturpação e fechamento de seu ser, "de-cai" na "inautenticidade", por estar lançada no mundo de maneira ambígua. Ela se mostra onticamente, segundo o modo da "aparência"; ontologicamente, a "pre-sença" está na não-verdade porque em sua essência é, "de-cadência", inautêntica em seu vivenciar. Em relação à ambigüidade do Falatório e da curiosidade, Heidegger nos fala:

"Em sua ambigüidade, o falatório e a curiosidade cuidam para que aquilo que se criou de autenticidade novo já chegue envelhecido quando se tornou público. A pre-sença é e está sempre "presente" de modo ambíguo, ou seja, presente na abertura pública da convivência, onde o falatório mais intenso e a curiosidade mais aguda controlam o "negócio", onde cotidianamente tudo e, no fundo, nada acontece" ...(Heidegger, p.235, 1989).

“... f falatório abre para a pre-sença, uma compreensão, o ser para o seu mundo, para os outros e para consigo mesmo, mas de maneira a que esse ser para... conserve o modo de uma oscilação sem solidez. A curiosidade abre toda e qualquer coisa de maneira a que o ser-em esteja em toda parte e em parte alguma. A ambigüidade não esconde nada à compreensão da pre-sença, mas só o faz para rebaixar o ser-no-mundo ao desenraizamento do em toda parte e em parte alguma..." (Heidegger, p.238, 1989).

- A mãe, "ser-com" os outros e com o filho portador de malformação congênita, demonstra apego e se abre no "pre" da "pre-sença" na "preocupação" e no "cuidado". 
Com relação às preocupações maternas, zejamos os discursos:

“...Eu e o pai cuidávamos dela como se fosse uma criança normal,... Por isso queria logo fazer a cirurgia. Só contei às pessoas mais íntimas, não queria que ninguém soubesse. ... todos gostam dela, é como se nada tivesse acontecido, são poucos os que sabem do problema...". (Orquídea)

“...nunca rejeitei ele, fiquei triste porque nasceu assim, amo muito o meu filho, semipre amei, não faço diferença, os dois são iguais, trato da mesma forma, como se ele fosse normal...". (Rosa)

“...Só me preocupo com a coluna que está ficando torta, deformada com o peso desse lado.(chora, chora...) ... O pai dele fica muito preocupado, não quer que ninguém toque nele, os médicos não sabem o que ele tem!...". (Papoula)

As mães se preocupam, cuidam dos filhos, como nem toda mãe é capaz de fazer. O apego materno está presente, seja a criança "normal" ou com deformidade, apesar de, nas situação de malformação, as mães sentirem dificuldades na formação do vínculo em virtude de o filho imaginário não corresponder ao real, "o nascido". Elas demoram, mas o amor materno fala mais alto. É seu filho e não importa.

Heidegger fala da preocupação. O preocupar-se com algo ou com alguém é uma constituição primordial do ser da "pre-sença" "no-mundo" "com-os-outros", e "pre-sença" é, essencialmente, "ser-com" possui um sentido "ontológicoexistencial". E as mães "ser-com-os outros" e com o filho portador de malformação congênita se preocupa com os cuidados especiais dispensados a ele: necessidades e tratamento, ajudando-o a transpor as barreiras de suas limitações. A preocupação funda-se, segundo Heidegger, em:

"...A "preocupação", no sentido de instituição social de fato, por exemplo, funda-se na constituição da pre-sença enquanto ser-com. Sua urgência provém do fato de, na maior parte doc vezes e antes de tudo, a presença se manter nos modos deficientes de preocupação..." (Heidegger, p.173, 1989).

“...A preocupação se comprova, pois como uma constituição ontológica da pre-sença que, segundo suas diferentes possibilidades, está imbricada tanto com o seu ser para o mundo da ocupação quanto com o ser para consigo mesma. A convivência recíproca funda-se, antes de tudo e muitas vezes de maneira exclusiva, no que, assim, constitui uma ocupação comum..." (Heidegger, p.174, 1989). 
Para finalizarmos, passaremos a descrever as caracteristicas do existir autêntico encontrados no discurso de Rosa. Segundo Heidegger, o existir autêntico é aquele "onde o homem assume seu ser e luta para impor-se tal como é ${ }^{20 "}$. Sendo assim, assume suas possibilidades mais próprias.

\section{- A mãe demonstra angústia, enquanto ser da "pre-sença” que se abre na compreensão. E é lançada para o seu ser mais próprio "ser-no- mundo" à maneira da disposição.}

Vejamos o discurso de Rosa:

“... a cabecinlua era toda deformada, tinlua fenda na boca e os dedos emendados. Naquela hora pedi a Deus forças para suportar,...

...Graças a Deus que agora está tudo bem. Ele é uma pimentinha, não pára, mexe em tudo, não deixa nada quieto, é uma criança saudável, normal. Está fazendo cirurgia para separar os dedos, vai facilitar ele pegar as coisas...".

Nesta situação, a mãe, em suas possibilidades de "ser-no-mundo", se abre na compreensão de si mesma e dos outros. Compreende e interpreta a condição de ser "si mesma", pela aceitação do filho sem culpabilidade, mostrando-se na autenticidade do seu ser.

Ela se mostrou tranqüila durante toda a entrevista e beijava o filho com muito carinho. Nesse momento, estavam todos juntos: pai, mãe e os filhos. Havia harmonia, integração, engajamento, uma "familia perfeita", ou seja, não havia problema. Ela diz que foi dificil no começo, mas, hoje, não vê motivos para estranheza. Ele é uma criança normal. A mãe, ser da "pre-sença", se abre na compreensão, na verdade do seu ser, na autenticidade. Sobre a compreensão, Heidegger nos fala:

"...A pre-sença é de tal maneira que ela sempre compreendeu ou não compreendeu ser dessa ou daquela maneira. Como uma tal compreensão, ela "sabe" a quantas ela mesma anda, isto é, a quantas anda o seu poder-ser. Esse "saber" não nasce primeiro de uma percepção imanente de si mesma, mas pertence ao ser do pre da pre-sença que, em sua essência, é compreensão. Compreender é o ser existencial do próprio poder ser da pre-sença de tal maneira que, em si mesmo, esse ser abre e mostra a quantas anda seu próprio ser. Trata-se de apreender ainda mais precisamente a estrutura desse existencial..." (Heidegger, p.199- 200, 1989).

“...A angústia sintetiza a pre-sença em seu próprio ser-no-mundo que, na compreensão, se projeta essencialmente para possibilidades. Naquilo pelo que se angustia, a angústia abre a pre-sença como ser-possível e, na verdade, como aquilo que, somente a partir de si mesmo, pode singularizar-se numa singularidade..." (Heidegger, p.251-252, 1989).

${ }^{20}$ BEAINI, T. C. $(1981$, p. $79-87)$. 


\section{CONSIDERAÇÕES FINAIS}

O "Ser-Mãe" vivenciador da experiência com o filho portador de malformação congênita é um "ser-ai", é um "ser-aí" "com-o-filho" e "com-os-outros", cujo modo de "ser-no-mundo" é a maneira do seu próprio ser, é a maneira de estar "nomundo", de se fazer presente como tal. Este vivenciar materno funda-se na maneira, no modo próprio de a mãe existir como ser dos entes encarnados e intramundanos à maneira da ocupação.

Esta interpretação é obtida fenomenologicamente na estrutura originária do ser da "pre-sença", da maneira como a mãe se mostra, se apresenta "no-mundo" em seu movimento existencial, determinando suas possibilidades e seu modo de ser e de se tornar presente, ser "junto-ao-mundo"; "ser-com", o ser próprio.

As mães(Margarida, Acácia, Dália...), em seu modo de ser cotidiano, se mostram na mobilidade da "de-cadência", é o que caracteriza o ser dos entes intramundanos, pela existencialidade e facticidade, cujas características fundamse na "ambigüidade" do "falatório" e da "curiosidade". Estas, por sua vez, mostram a mobilidade da "de-cadência" em suas funções essenciais de tentação, tranqüilidade, alienação e aprisionamento e, por outro lado, a angústia que subsiste na possibilidade da abertura privilegiada da "pre-sença" em sua singularidade.

Já aquela mãe (Rosa) que se angustia se abre na "pre-sença" como um ser possivel, como ser próprio, como um ser autêntico. Ela se angustia com o serimperfeito no mundo-lançado. A angústia de que fala Heidegger é a própria existência humana, existência autêntica, que se liga ao nivel da vivência. E a mãe, enquanto "pre-sença" "no-mundo", angustia-se por aquilo "que se mostra em si mesmo". É, a partir deste sentimento profundo, que se abrem as possibilidades para o "Ser-Mãe" de crianças portadoras de malformação congênita: a fuga na mobilidade da "de-cadência", o esquecimento de si mesma, destruição do "eu" (inautenticidade) ou o retorno à dimensão cotidiana, o transcender e superar a sua própria angústia, a verdadeira aceitação sem culpabilidade, buscando um sentido para a vida (autenticidade).

Neste trabalho, nos depoimentos maternos, encontramos as unidades de significação que iluminaram a trajetória em busca do sentido, da direção das mães, da sua maneira de ser, da sua maneira de vivenciar, de apreender e de conter o mundo.

Enquanto grupo de mulheres que têm filhos portadores de malformação congênita, elas o vivenciam de uma maneira similar. Podemos dizer que, em sua maioria, vivenciam o mundo no impessoal, no mundo de todos, na "ambigüidade" do "falatório" e da "curiosidade", embora, em sua individualidade, cada uma em particular vivencia o evento de forma singular. 
Encontramos na dimensão da facticidade: as manifestações de culpa, medo, angústia, vergonha, apego, cuidado, negação(rejeição) e aceitação. Na dimensão do fenômeno, encontramos: humor, temor, ambigüidade, falatório, curiosidade, preocupação e compreensão, velados nas manifestações.

Compreender a mãe em seu vivenciar o dia-a-dia com o filho portador de malformação congênita é de extrema importância para nós, profissionais da saúde, para que possamos visualizar o ser em sua dimensão vivencial, com suas limitações e fragilidades, proporcionando-the medidas de prevenção dos traumas provenientes do "momento da notícia", no diagnóstico precoce (pré-natal) ou tardio (pós-natal), pois, nesta situação, os pais necessitam de ajuda, apoio, orientação e compreensão para que possam ajustar-se como pessoas; procurando atender às mães e elementos da família em suas necessidades humanas básicas, visualizando-as no sentido holístico, interagindo no ambiente dinâmico como um todo, segundo as concepções teóricas de enfermagem de Myra Estrin Levine $^{21}$, e adaptando-nos ao pensamento Heideggeriano, podemos dizer, o ser em sua totalidade.

Buscando o acolhimento, interação, afinidade, conhecimento recíproco, compreensão e aceitação enfermagem-mãe-família, agindo em tempo determinado, prolongado ou não, vislumbrando a atenção primária, secundária e terciária de saúde materno infantil.

Para atendermos esta clientela de forma eficiente e. eficaz, é necessário que tenhamos conhecimentos e habilidades para assistir a este binômio, desenvolvendo um trabalho de orientação e encaminhamento. Sinason ${ }^{22}$ nos alerta para o fato de que, se não for fornecido treinamento adequado aos futuros profissionais da área de saúde, em relação à maneira como dar a notícia aos pais e familiares, estes terão seu choque ampliado.

Este estudo fornece, não só ao profissionais de enfermagem mas a toda equipe de saúde, uma compreensão do "Ser-Mãe" de criança portadora de malformação congênita e deteç̧ão de seus problemas. $E$ é, de fundamental importância que o enfermeiro, a partir destas informações e deste novo olhar, procure uma maneira de levar as mães a se aceitarem a si mesmas, sendo "no-mundo" com-o-filho". Ensinar-Ihes a cuidar do filho, eliminando seu sentimento de culpa, ou seja, seu "temor" e assim aceitando a condição em que foi projetada "nomundo".

${ }^{21}$ GEORGE, J. B. e Cols. Teorias de Enfermagem: Os Fundamentos para a Prática Profissional. Porto Alegre, Artes Médicas, 1993. p.164 -173.

${ }^{22}$ SINASON, V. Compreendendo seu Filho Deficiente. Trad. Sérgio Nunes Melo, Rio de Janeiro, IMAGO, 1993. p.33. 
Com esta abordagem e com o referencial de Martin Heidegger, o enfermeiro desvela-se a si mesmo e proporciona o desvelamento do outro, à medida que busca a compreensão do outro e de si mesmo. O ser enfermeiro intenciona e direciona as suas ações às mães e a seus filhos, portadores de malformações congênitas. Ele direciona suas ações, desde o nascimento quando as mães vivenciam momentos de choque, para elaborar um plano assistencial que supra as necessidades emergenciais da criança e da mãe.

\section{BIBLIOGRAFIA.}

1. BEAINE, T. C. À Escuta do Silêncio: Um Estudo Sobre a Linguagem no Pensamento de Heidegger. São Paulo: Cortez, 1981.

2. BOEMER, M. R. A Condução de Estudos Segundo a Metodologia de Investigação Fenomenológica. R. Lat. Enferm. Ribeirão Preto, v.2, n.1, p.83-97, jan. 1994.

3. CAPALBO, C. Fenomenologia e Ciências Humanas. Rio de Janeiro: Âmbito Cultura Edições, 1987.

4. Alternativas Metodológicas de Pesquisa. In: SEMINÁRIO DE PESQUISA, III, Anais, Florianópolis/SC, ed. da UFSC, p. 130-157, 1984.

5. CAPAlBO, C. A História do Ser Humano Segundo Merleau-Ponty. R. Bras. Filos., São Paulo, v.39, n.157, p.3-17, jan/ fev/mar.1990.

6. Abordando a Enfermagem a Partir da Fenomenologia. R. Enferm. UERJ, Rio de Janeiro, v.2, n.1, p.70-76, mai. 1994.

7. CARVALHO, A .S. Metodologia da Entrevista: Uma Abordagem Fenomenológica. Rio de Janeiro: Agir, 1987.

8. DONZELLI, T. A. Método Fenomenológico e Ciências Humanas. In: Teorização do Serviço Social - Documento Alto da Boa Vista. Rio de Janeiro: Agir CBCISS, 1988. p.45-49. 
9. DONZELLI, T. A, Cotidianidade e Dimensões Sociais do Homem. Debates Sociais, Rio de Janeiro, v.24, n.47, p.54-62, jul/dez. 1988.

10. Anotações de Aula-Disciplina de Filosofia Contemporânea. Curso de Especialização em Enfermagem - UERJ, 1994.

11. Ańotações de Palestra - Eutanásia: Aspectos Filosóficos. Curso de Doutorado em Medicina - UFRJ, 1994.

12. FORGHIERI, Y. C. e cols. Fenomenologia e Psicologia. São Paulo: Cortez, 1984.

13. FROSSARD, Selma. As Dimensões do Mundo da Vida e a Formação Profissional do Assistente Social. Rio de Janeiro,1992. Dissertação (Mestrado) - Escola de Serviço Social, Universidade Federal do Rio de Janeiro.

14. GEORGE, J. B. e cols. Teorias de Enfermagem. Porto Alegre: Artes Médicas, 1993.

15. GoRmAN, R. A. A Visão Dual. Trad. Livia Neves de Holanda Barbosa. Rio de Janeiro: Zahar, 1979

16. HEIDEGgeR, M. Ser e Tempo. Trad. de Márcia de S. A. 3.ed. Petrópolis: Vozes, 1989. v.1.

17. Todos Nós Ninguém. Trad. Maria Dulce Critelli e Solon Sponoudis. São Paulo: Morais, 1981.

18. MARTINS, J., BOEMER, M. R. \& FERRAZ, C. A. A Fenomenologia como Alternativa Metodológica para Pesquisa: Algumas Considerações. $R$. Esc. Enferm. USP, São Paulo, v.24, n.3, p.139-147, abr. 1990.

19. MARTINS, J. \& BICUDO, M. A. V. A Pesquisa Qualitativa em Psicologia: Fundamentos e Recursos Básicos. São Paulo: Morais, 1989.

20. MORA, J. F. Dicionário de Filosofia. Lisboa: Dom Quixote, 1982. 
21. PINHEIRO, M. C. D. O "Ser-Mãe" de Criança com Malformaçāo Congênita: Um Estudo à luz de Martin Heidegger. Rio de Janeiro, 1995. Dissertação (Mestrado em Enfermagem). Universidade do Rio de Janeiro-UNIRIO.

22. SINASON, V. Compreendendo o Filho Deficiente. Trad. Sérgio Melo. Rio de Janeiro: IMAGO, 1993. 